УдК 316.723

\title{
СТРАТЕГИИ ВИЗУАЛИЗАЦИИ ПОСТАПОКАЛИПСИСА В СОВРЕМЕННОЙ МАССОВОЙ КУЛЬТУРЕ
}

\author{
Некита Андрей Григорьевич, \\ beresten@mail.ru \\ Маленко Сергей Анатольевич, \\ olenia@mail.ru \\ Суслова Елена Петровна, \\ polos123@mail.ru
}

Новгородский государственный университет имени Ярослава Мудрого, Россия, 173003, г. Великий Новгород, ул. Большая Санкт-Петербургская, 41

Некита Андрей Григорьевич, доктор философских наук, профессор кафедры философии, культурологии и социологии Новгородского государственного университета имени Ярослава Мудрого.

Маленко Сергей Анатольевич, доктор философских наук, профессор, заведующий кафедрой философии, культурологии и социологии Новгородского государственного университета имени Ярослава Мудрого.

Суслова Елена Петровна, студентка кафедры философии, культурологии и социологии Новгородского государственного университета имени Ярослава Мудрого.

Актуальность. Тотальная экспансия экранной культуры создает новые тренды, которые обуславливают возникновение новой антропологической ситуации. Современный человек перестает наслаждаться привычными образами, связывающими его фантазии с реальностью. Он намеренно и демонстративно стремится окружить себя деструктивными образами, всякий раз подчеркивающими усугубляюшуюся остроту проблем современной цивилизации. Поэтому появление и бурное развитие жанра постапокалипсиса выступают визуализацией фантазий обывателя по поводу острой необходимости прекращения страданий человека и природы в рамках сложившихся форм цивилизационной коммуникации. Цель: проанализировать своеобразие постапокалиптических сюжетов в современном искусстве и кинематографе, опирающихся на теоретическое наследие новейшего времени. Методы: компаративистский, психоаналитический и семиотический методы интерпретации широкого поля современной массовой культуры. Результаты: идея конца истории приобрела особую актуальность в начале XX в., когда в Европе разразился всесторонний социокультурный кризис. Выдающиеся умы попытались ответить на сложнейшие противоречия, с которыми впервые столкнулось человечество. Нарастающие социальные противоречия все чаще начинают рассматриваться как знаки грядущего конца цивилизации, которая погрязла в унификации, безответственности власти и пассивности масс. Такая рефлексия подготовила формирование художественного опыта визуализации фундаментальных противоречий цивилизации, которые особенно обострились на рубеже XX-XXI вв. Несмотря на преимущественно досуговый характер современного массового искусства, оно избирает именно эту тему в качестве магистрального направления своего развития. Литература, музыка, живопись, комиксы, анимация и компьютерные игры активно используют сюжеты конца истории для воссоздания напряженного ожидания неминуемой расплаты человечества за безответственное отношение к природе и человеку. Современная киноиндустрия занимает особое место в решении этой задачи, поскольку в ее распоряжении находятся исключительные выразительные средства и наиболее массовая аудитория. Выводы: фантастическая популярность темы постапокалипсиса выходит за рамки обычных культурных индустрий и уверенно превращается в форму идеологической визуализации ключевых социокультурных противоречий эпохи. Подобная управленческая технология расценивается авторами как пропедевтика 
нового качества современной цивилизации, насильственно разрывающей генетические связи с природой, культурой и традищией.

Ключевые слова: Постапокалипсис, идеология, искусство, массовая культура, кинематограф, кризис цивилизации, конец истории.

\section{Постапокалипсис цивилизации в теоретических проекциях}

На протяжении десятков веков историки, писатели, художники и философы достаточно настойчиво пытались предугадать ход развития цивилизации. Совершенно естественно, что каждый из них по-разному представлял себе не только ближайшее, но и отдаленное будущее. Писатели, например, воплощали свои пророческие идеи в антиутопических романах и фантастических рассказах, тогда как многие философы и историки размышляли о предстоящем будущем в более строгой, свойственной для их интеллектуального круга манере. В частности, именно они настойчиво предвещали наступление апокалипсиса, считая его не только закономерной, но и главное - абсолютно неизбежной стадией социокультурной и политической эволюции человечества. К тому же, заметим, что по целому ряду мировоззренческих причин зарубежные и российские авторы неоднозначно интерпретировали общую, казалось бы, для всех тему кризиса цивилизации и культуры рубежа XIX-XX вв.

Так, среди зарубежных мыслителей, настойчиво и продуктивно исследовавших проблему грядущей гибели западной цивилизации, а также сформулировавших значимые и достаточно обширные предсказания по этому поводу, наиболее известными являются: О. Шпенглер, создавший знаменитый труд «Закат Европы»; Ж. Бодрийяр и Э. Сиоран, осветившие эту острую во всех смыслах проблему в трудах, вошедших в книгу «Матрица Апокалипсиса. Последний закат Европы»; Р. Генон, также предвещавший закат западной цивилизации в книге «Кризис современного мира»; А. Тойнби, основные мысли которого изложены в сборнике «Постижение истории»; П. Бьюкенен, который в своей книге «Смерть Запада» настойчиво обращал особое внимание на целый ряд факторов, которые в результате могут привести к сокрушительному падению западной цивилизации.

Среди российских авторов, продуктивно работавших «на ниве» осмысления грядущего апокалиптического будущего человечества, можно отметить Н.Я. Данилевского, создавшего уникальный философский труд «Россия и Европа»; П.А. Сорокина с его особенным взглядом на кризис западной цивилизации, изложенным в сборнике его трудов «Человек. Общество. Цивилизация», а также более современного российского исследователя А.П. Назеретяна, чьи размышления о целом комплексе острейших цивилизационных проблем представлены в книге «Цивилизационные кризисы в контексте Универсальной истории».

Вкратце рассмотрим и проанализируем лишь некоторые из указанных выше концепций. Пожалуй, одним из самых знаменитых «пророков», предсказавших драматический и откровенно безрадостный «конец Запада», является О. Шпенглер. Его книга «Закат Европы», изданная в двух томах в начале XX в., имела сенсационный успех, прежде всего потому, что в ней мыслитель развернуто представил свои идеи по поводу неизбежной гибели западной цивилизации как раз в то самое время, когда сама Европа ещё достаточно успешно развивалась и прогрессировала. По мнению западных идеологов, Запад на протяжении многих веков являлся наглядным примером, эталоном, в некотором роде даже своеобразной лабораторией «по производству общечеловеческих ценностей» [1], на которые следовало неуклонно равняться и которых должны строго придерживаться все, закономерно отстающие в своем развитии народы. 
В связи с этим российский исследователь Ф.А. Степун считал, что книга О. Шпенглера потому и имела огромный успех, что была создана сразу после колоссальных мировых потрясений (ужасной войны и целой череды революций), став своего рода знаковым вызовом существующей науке [2]. Чем же так потрясла мир эта необыкновенная книга? Прежде всего тем, что автор решительно и бескомпромиссно противопоставил культуру и цивилизацию. Философ отрицал линейное развитие всемирной истории, признавая логичным одновременное и отдельное существование множества культур. При этом, по его мнению, каждая из них все-таки имеет как свою собственную судьбу, так и «свои новые возможности выражения, которые появляются, созревают, увядают и никогда не повторяются, собственную идею, собственные страсти, собственную жизнь, волнения, чувствования, собственную смерть» [3]. Показательно, что Шпенглер закономерно и в духе характерных для своей эпохи биологизаторских тенденций сравнивал культуру с живым организмом, который развивается по определенному сценарию: рождение, детство, зрелость, старость и гибель. При этом за смертью культуры непременно следует приход цивилизации, для которой характерны холодная рациональность, практичность, равенство, унификация, прагматизм, расширение территории, неудержимое стремление к богатству и власти, но вместе с тем социальная и техническая обеспеченность.

Вообще цивилизация традиционно понимается нами как высшая ступень развития человечества, основанная на развитом высоком интеллекте, справедливости, толерантности, значимых и неоспоримых достижениях науки и техники. О. Шпенглер не видит ничего плохого в успехах цивилизации, поскольку, несомненно, он и сам пользовался и новой техникой, и не виданными ранее удобствами, обусловленными ее появлением. Однако философ, по нашему убеждению, смотрел гораздо дальше и прежде всего опасался, что в безумной гонке за видимым и всегда условным благополучием у людей совершенно не останется времени ни на культуру, ни на близких, ни на самих себя. А ведь культура - это источник и пространство для развития искусства, творчества, индивидуальности, формирования и развития уникальной личности. Культура многогранна, элитарна, основана на религии, на мифе. И как раз в силу этих причин культурный человек постоянно заботится о собственном душевном состоянии, старательно, вдумчиво и прочувствованно, наполняя себя внутренней энергией. В цивилизации же, по мнению философа, нет места для творчества, индивидуальности, духовности, патриотизма. Ей присущи уничтожающая различия утилитарность, взрывное развитие техники, неуклонное оскудение искусства и литературы, страдания и парадоксальное одиночество людей, сбитых в толпы и стада в «резервациях» перенаселенных городов, перенасыщенность техникой, неуемная жажда зрелищ и спортивных состязаний, появление безликих масс, стремительно деградирующих фоне стремления элит к мировому господству, обогащению.

Таким образом, именно в прогрессирующем наступлении цивилизации Шпенглер видит залог непременной гибели Запада, а между строк книги достаточно остро читается призыв к современникам во что бы то ни стало оставаться культурными людьми, ценить, понимать и любить культуру.

Вслед за работой О. Шпенглера на европейском культурном ландшафте появляется исторический труд А. Тойнби под названием «Постижение истории». Тойнби также признает существование и многообразие различных культур, только в своей работе упор делает на исследовании обществ, которые превращаются в цивилизации. В отличие от Шпенглера Тойнби не считает цивилизацию живым организмом и отвергает утверждение, согласно которому цивилизация проживает жизнь длиною в тысячу лет: 
«Догматически твердить вслед за Шпенглером, что каждому обществу предопределен срок существования, столь же глупо, как и требовать, чтобы каждая пьеса состояла из одинакового числа актов» [4].

По мнению исследователя, успешно развивающаяся цивилизация - это общество, состоящее из творческого меньшинства, за которым следует большинство, сформированное из пролетариата внутреннего и внешнего (соседние народы). Развитие цивилизаций всегда связано с окружающими условиями: войны, стихийные бедствия, суровый климат и т. д. Творческое меньшинство должно своевременно отреагировать на возникшие обстоятельства и решить проблему. Для роста цивилизации не характерны технический прогресс, внутренние социальные конфликты, стремление к обогащению и власти. Однако после ее бурного развития непременно следует спад, надлом, за которым неизбежно наступают разложение и гибель цивилизации.

Период от надлома до гибели цивилизации может длиться довольно продолжительное время - от ста до тысячи лет. Во время подобного упадка творческое меньшинство теряет свои способности справляться с природными и социальными вызовами, а большинство перестает слепо верить элите. Именно поэтому творческое меньшинство, желающее удержаться на вершине власти, вынуждено применять насилие, чему не только сопротивляется внутренний пролетариат, но и в этом же направлении активизируется и внешний. Затем наступает эпоха вражды, которая неуклонно влечет цивилизацию к исчезновению. Внутреннему пролетариату не остается ничего, кроме как решительно отмежеваться от меньшинства и создать свою веру, которая может стать основой для новой цивилизации.

Тем временем внешний пролетариат продолжает активно нападать на угасающую цивилизацию, что неизбежно подтачивает ещё больше ее, приводит к половой распущенности населения, изменению принципов общества, опошлению и упрощению искусства, языка, науки, религии, деградации нравственных устоев. Изменить ситуацию может только преображение, предполагающее «перенос цели и ценностей в сверхчувственное царство Божие» [4], которое, конечно же, полностью остановить угасание не сможет, но в итоге вполне способно породить новую цивилизацию. В связи с этим А. Тойнби пишет: «Цель преображения - дать свет тем, кто погряз во тьме... Она достигается в поисках царства Божьего, чтобы привести его жизнь в действие... Таким образом, цель преображения - царство Божие...» [4]. Тойнби полагает, что западное общество находится в стадии надлома и разложения, но для смягчения падения и гибели, люди должны молиться, причем делать это с полным раскаянием.

Русский по происхождению, но впоследствии высланный в Америку и сделавший там очень успешную карьеру, социолог и культуролог Питирим Сорокин (как Шпенглер и Данилевский) выступал в роли «черного» пророка и обнародовал свои зловещие предсказания в книге «Социальная и культурная динамика», основные идеи которой вошли в сборник «Человек. Цивилизация. Общество». Выступая в качестве «черного пророка», Сорокин, как продемонстрировали последующие трагические события, целиком справедливо утверждал, что «войны и революции не исчезают, а напротив, достигнут в XX в. беспрецедентного уровня, станут неизбежными и более грозными, чем когда бы то ни было ранее; что демократии приходят в упадок, уступая место деспотизму во всех его проявлениях; что творческие силы западной культуры увядают и отмирают и т. д.» $[5$, с. 427$]$.

Показательно, что эти строки социолог писал в то время, когда мир еще не столкнулся ни с мировыми войнами, ни с разрушительными революциями, вокруг веяло буржуазным оптимизмом, впереди, как казалось, было только безоблачное и обнадежи- 
вающие будущее без зверств и кровопролитий. И, конечно, тогда такие высказывания закономерно воспринимались многими окружающими в штыки, подвергались критике, поднимались на смех, или же вовсе игнорировались. Но примерно через десть лет ситуация изменилась коренным образом. Все пророческие слова П. Сорокина нашли свое подтверждение в неоспоримых фактах: гибели миллионов людей, исчезновении процветающих городов, невиданной доселе эскалации голода, нищеты и страданий. Внезапно улетучился былой оптимизм, а вместе с ним безвозвратно канули в Лету и безопасность, мир и порядок, исчезли процветание и благополучие. «Солнце западной культуры закатилось. Громадный вихрь накрыл собой все человечество» [5, с. 428]. Стало ясно, что в мире наступил глубочайший кризис, затронувший всю западную культуру и общество. Этот кризис, проник во все сферы общественной жизни, затронул образ мыслей и поведение, свойственные западному обществу. Сорокин справедливо считал, что подобные явления наиболее наглядно выразятся «в распаде основополагающих форм западной культуры и общества последних четырех столетий» [5, с. 429].

Следует указать, что П. Сорокин, в отличие от Шпенглера, предвещавшего неминуемую гибель Западу, имел принципиально иную позицию. Он полагал, что человечество не раз уже переживало цивилизационные кризисы, а потому гарантированно переживет и этот. Также он не был согласен и с утверждением Шпенглера о том, что культура как живой организм проходит стадии от рождения до смерти, считая его теории, особенно касающиеся смерти западной культуры, беспочвенными, неубедительными и бездоказательными. Тщательно изучив кризис западной культуры, социолог не признает «гибель» Запада. Поскольку кризис, по Сорокину, - это всего лишь замена одной фундаментальной формы культуры на другую. Так, в западной культуре в конце Средних веков на смену идеациональной социально-культурной форме, в рамках которой главной ценностью являлся Бог, пришла форма чувственная. Сейчас же мы переживаем такое время, когда разрушается чувственная форма, а на смену ей непременно придет другая форма культуры - интегральная, основанная на сотрудничестве и альтруистической любви. «Именно великая энергия альтруистической любви - источник прогресса общества, воспитания детей в духе доброты и творчества, зарождения и возвышения мировых религий», - утверждал Сорокин [6].

Известный французский философ Ж. Бодрийяр по-своему интерпретировал грядущий апокалипсис культуры, к которому, по его мнению, неумолимо движется современное общество. Философ вводит понятие «гиперреальность», значение которого примерно тождественно термину «симуляция». Гиперреальность, по его мнению, сегодня проникла во все сферы человеческой деятельности, поглотила и политику, и культуру, и социальные взаимоотношения. Гиперреальности свойственна избыточность, поэтому людей окружает сумасшедшее количество информации, которую надо отбирать. Кроме того, она же предполагает «прозрачность», в рамках которой вся жизнь человека выставляется напоказ, все оказывается доступным, в том числе во многом и через социальные сети, а также виртуальность, бич XXI в. и зависимость от публичности. При этом трагически утрачивается индивидуальность, приватность, исчезают действительные ценности, наступает духовный и творческий застой, общество погружается в пучину стагнации.

В своей книге «Символический обмен и смерть» Бодрийяр приходит к выводу, что именно сейчас наступил апокалипсис современного искусства. Настоящее искусство заменил симулякр - «образ, лишенный сходства с предметом, но создающий эффект подобия» [7]. Современное искусство полностью пронизано виртуальной реальностью, которая не имеет ничего общего с действительностью. Впрочем, философ счита- 
ет, что не только современное искусство, но и вообще всю современную действительность можно назвать симулякром.

В таком гиперреальном мире люди неуклонно превращаются в массу, представляющую собой, по Бодрийяру, «молчаливое большинство». Парадокс, но сбитому в массу обществу чужда социальность, поскольку масса изначально асоциальна, наоборот, его отличают примитивность, упрощение, одинаковость, изобилие маргинальных языков, разрушение системных ценностей. В работе, включенной в сборник «Матрица Апокалипсиса. Последний закат Европы», Бодрийяр так характеризует молчаливое большинство: «это не сущность и не социологическая реальность, это тень, отбрасываемая властью, разверзнувшаяся перед ней бездна, поглощающая ее форма. Текучее, неустойчивое, податливое, слишком быстро уступающее любому воздействию скопление, характеризующееся гиперреальным конформизмом, крайней степенью пассивности...» $[8$, c. 57]. Безмолвие и безразличие масс Бодрийяр и считал главной проблемой современности, которая рано или поздно непременно приведет к апокалипсису.

Темой грядущего апокалипсиса насквозь пропитаны и произведения французского философа румынского происхождения Э. Сиорана. Он был жутким пессимистом и скептиком, с детства думал о смерти и жил «на обочине, подобно паразиту» [9, с. 4]. Коротко охарактеризовать его произведения можно несколькими словами: агония, катастрофа, зло, упадок, конец, крах, ложь. В указанном выше сборнике собраны наиболее значимые произведения Сиорана, в которых философ, как и отмеченные нами ранее его предшественники, недвусмысленно пророчит гибель Западу. Мыслитель во многом поддерживал Шопенгауэра в убеждении, что в мире намного больше зла, чем добра, находя отголоски этого мнения и в собственной жизни, с грустью замечая, что современное ему человечество буквально утопает в заполонившем все и вся зле. Сиоран уверен, что конец истории непременно наступит уже хотя бы потому, что когда-то же она началась. А сейчас, по мнению ученого, все мы «стремительно несемся к горизонтам апоплексии, к зловещим чудесам, к золотому веку ужаса» [10, с. 102]. У философа даже возникают откровенно суицидальные мысли, он искренне не понимает, зачем ждать агонии перед смертью, когда можно покончить с этим здесь и сейчас, т. е. самоуничтожиться.

Наступившее время упадка цивилизации, с точки зрения румынского автора, дано людям лишь для того, чтобы они задумались о своем существовании, осознали, какими идеалами живут, на каких кумиров равняются, какими достижениями гордятся, чтобы они, наконец, пришли в себя и отрезвились бы. Но, увы, а потому впереди человечество ожидает лишь неминуемая катастрофа. И если Шпенглер определил временные рамки существования цивилизации длиной в тысячу лет, то Сиоран не говорит о точных сроках конца исторического процесса, ведь он может наступить внезапно или растянуться на долгие годы. Но благодаря своим достижениям, человечество стремительно скатывается в пропасть, убежден мыслитель. Человек будущего, для Сиорана, - это человек, обессиливший, не строящий из себя исключительного, с абсолютно «опустошенным сознанием, которое нечем заполнить» [10, с. 82]. Философ представляет себе очень мрачное будущее, в котором «все станет невозможным, непереносимым, а единственным достойным делом для тех, кто останется жить, будет уничтожать себя и себе подобных» [10, с. 82].

На наш взгляд, Сиоран в своих произведениях дает очень актуальный совет для современного общества. Философ рекомендует массовому человеку довольствоваться тем, что есть, не пытаясь что-то поменять, иначе это будет лишь пустая трата времени. Он должен желать лишь того, что крайне необходимо, в противном случае наступит 
крах, и обязан «попытаться жить вглубь, чем нестись сквозь столетия в погоне за гибелью» $[10$, с. 83$]$.

Неутешительные прогнозы о судьбе западной цивилизации представлены и в книге «Смерть Запада» известного американского политика П. Бьюкенена. Автор провел ряд исследований и выявил, что вымиранию западной цивилизации грозит ряд глобальных опасностей: депопуляция западных стран, массовая иммиграция, размывание национальных границ, культурная революция. Надо отметить, что «Запад» как геополитическая реальность для Бьюкенена включает и Центральную, и Восточную Европу, в том числе и Россию, по причине того, что во всех этих странах практически одна религия - христианство.

Более всего Бьюкенен озабочен нынешним демографическим кризисом, провозглашая факт «умирания» Запада, он с горечью замечает, что живущее на его просторах население стремительно вымирает. Люди «перестали воспроизводить себя, население западных стран стремительно сокращается... Нынешний кризис грозит уничтожить западную цивилизацию» [11]. Свои доводы автор подтверждает неопровержимыми фактами, основанными на статистике и научных исследованиях. Например, политик называет семнадцать стран (преимущественно западных), в которых смертность на порядок выше рождаемости, и делает печальные прогнозы. К 2050 г. население европейского происхождения будет составлять лишь 1/10 часть от всего мирового населения, а большая ее часть будет образована выходцами из стран «третьего мира» - Африки, Азии, Южной Америки. Низкая рождаемость к 2050 г. приведет к увеличению пожилого населения на треть населения Западной Европы, т. е. значительно снизится часть трудоспособного населения. Для ее восполнения, считает Бьюкенен, а также для обеспечения комфортной жизни пожилого населения властям просто необходимо будет открыть двери огромному количеству иммигрантов. В свою очередь, их массовый наплыв постепенно вытеснит местные обычаи, нравы, правила, веру, нравственные ценности, местную культуру. «В девятнадцатом столетии Европа колонизировала Африку; в двадцать первом веке Африка колонизирует Европу», - не без оснований предполагает Бьюкенен [11].

Сам Бьюкенен в своей книге утверждает, что «смерть Запада» - это не прогноз будущего, а выявление фактов, происходящих в данный момент. С грустью он констатирует тот факт, что народы «первого мира» вымирают» [11]. И если женщины западных стран не одумаются, не перестанут ценить комфортные условия, карьеру, независимость выше, чем свое прямое предназначение - материнство, то отстающие страны полностью поглотят собой высокоразвитые страны.

Таким образом, коротко рассмотрев концепции представленных авторов, можно сделать следующий вывод. Так или иначе, все проанализированные выше мыслители сходятся во мнении, что наступление гибели западной цивилизации абсолютно неизбежно. Разнятся лишь только причины, которые неумолимо приближают нас к апокалипсису. Исследователь Connor Pitetti так резюмирует наши рассуждения: «Апокалиптические повествования используют идею конца, чтобы придать структуру опыту истории. Описывая конец как момент разрыва, который создает абсолютное разделение между старым и новым мирами, они представляют историю как серию четко определенных и, следовательно, понятных переходов между различными моментами или эпохами. Постапокалиптические повествования усложняют этот аккуратно организованный рассказ, описывая “концы” как сложные исторические трансформации, которые включают пережитки и непрерывности и, таким образом, размывают различия до/после» [12, p. 437]. Также по-разному авторы видят и пути выхода из кризисной си- 
туации. Но как бы ни призывали философы, социологи, культурологи и политики своих читателей, да и мир в целом, одуматься, отрезвиться от интоксикации товарнопотребительским и сервильным гедонизмом, современное западное общество, увы, пока не внемлет их советам, а продолжает жить в свое удовольствие, уничтожая природу с использованием всевозможных достижений науки и техники, а главное - все глубже увязая в массовых тренажах по расширенному воспроизводству симулякров, существенно затрудняющих и ограничивающих меру понимания и свободы в человеческой жизни.

\section{Художественный опыт осмысления конца истории}

Начиная с XIX в. развитые страны Европы и США вступают на новый путь развития, суть которого состоит в стремительном переходе от традиционной аграрной культуры к индустриальной. В результате промышленной революции небывалыми темпами строятся заводы и фабрики, происходит бурный рост городов, вокруг которых и возводились новые предприятия, а трудоспособное население (преимущественно молодежь) из деревень массово, в добровольно-принудительном порядке переселяется в города. Внезапно оторванные от своих семей, от привычной и размеренной крестьянской жизни, молодые люди оказываются в совершенно чужой и откровенно чуждой, враждебной для них обстановке. Ими массово овладевают чувство потерянности, искреннее непонимание тех искусственных норм, правил и ценностей, пленяющих новоявленных жителей мрачных городов. Местное население не принимает их, смеется и издевается над ними, называя «деревенщиной» и приклеивая ярлыки «понаехавших».

Потому вырванной из привычной жизни молодежи ничего не остается делать, как изначально обособиться от «коренных горожан» и продолжать взаимодействовать с себе подобными. В процессе такой коммуникации начинает зарождаться принципиально новый тип культуры. Парадоксально, но именно так и формировалась урбанистическая маргинальная культура: уже не аграрная, с присущими той мифами, сказками, традициями, но ещё и не городская. Это и были зачатки самой настоящей массовой культуры. Надо отметить, что новая прослойка общества состояла не только из деревенской молодежи, но и из депрессивных, искалеченных жизнью молодых людей, только вчера вернувшихся с войны (имеется в виду Первая мировая война), которые воочию видели ужасные убийства, кровопролитие и стремились выжить любой ценой. Поселившиеся в городах бывшие солдаты интересовались лишь насущными вопросами: искали пропитание, жилье, развлечения и совершенно не находили умиротворения в звуках природы, пении птиц, в любовании рассветами и закатами. Такое массовое общество изначально характеризовалось затаенной злобой, глубоким страхом, немотивированной агрессивностью, вандализмом. Людям всерьез казалось, что весь мир против них, потому они и объединялись в городские банды для выживания, при любом удобном случае выплескивая агрессию по отношению к этому самому миру.

Таким образом, формирующееся массовое общество закономерно порождает соответствующий тип культуры, базирующийся на удовлетворении двух основных инстинктов - Эроса (стремление к жизни, продолжению рода) и Танатоса (стремление к смерти, к разрушению, к агрессии, к уничтожению). Массовая культура в первую очередь выполняет вытесняюще-сублимативную функцию, поскольку позволяет человеку перенаправлять негативную энергию, раздражительность, подыскивать объект для разрушения и уничтожения не только в реальности, но и «проигрывать» свои эмоции. Например, в компьютерной игре, уничтожая виртуальных врагов, или в ходе просмотра фильма, сопереживая героям, давая волю подавленным цивилизацией инстинктам. 
Другими словами, массовая культура позволяет сохранить в обществе иллюзию стабильности, что немаловажно. Ведь в XX в. произошло немало глобальных событий череда революций, две мировые войны, появление химического, а затем и ядерного оружия, которое может уничтожить все живое на Земле, глобальное потепление, которое также может привести к вымиранию человечества и всей природы, природные и техногенные катастрофы, терроризм. Все эти события послужили появлению такого комплексного художественного жанра, как апокалиптика. Несмотря на то, что идея конца света существовала во всех исторических эпохах, наиболее широкое и полное распространение она получила в XX в. Катастрофическое сознание сделало свое дело. Тема апокалипсиса проникает и находит свое отражение практически во всех видах искусства: в литературе, музыке, кинематографе, картинах современных художников, комиксах, карикатурах, компьютерных играх. Именно поэтому Ö̈gür Yaren справедливо утверждает, что социокультурная «конъюнктура, которая формируется несколькими совпадающими нарративами кризиса от антропоцена до более позднего политического кризиса растущего популизма, привела к тому, что постгуманистический дискурс получил широкое распространение» [13, с. 77].

Проследим, как именно тема апокалипсиса и постапокалипсиса отразилась во всех этих жанрах. Невероятное количество литературных произведений написано в жанре постапокалиптики. Следует указать, что постапокалиптика - это собирательный жанр научно-фантастической литературы и кино, повествующий о жизни остатков цивилизации после некой глобальной катастрофы. Апокалиптических сюжетов существует великое множество: вторжение инопланетян или других нечеловеческих существ, эпидемия, вирусы, борьба с искусственным интеллектом, природные и техногенные катаклизмы, биологическое и ядерное оружие, гибель окружающей среды от неразумной и хищнической деятельности человека, восстание мертвецов (зомби-апокалипсис).

Первым автором, которая создала литературное произведение в этом жанре, была английская писательница Мэри Шелли. Ее роман «Последний человек», описывающий мир будущего после эпидемии чумы, был опубликован в далеком 1826 г. и потерпел полную неудачу. Произведение подверглось насмешкам публики и многочисленных критиков, вероятно из-за того, что тема постапокалипсиса в то время не была ещё такой актуальной. В 1885 г. английским писателем Ричардом Джеффрисом был написан роман «После Лондона», действие которого происходит после катастрофы, отбросившей человечество в Средневековье. В 1898 г. выходит всемирно знаменитый научнофантастический роман, очень популярный и в наше время, - «Война миров» Герберта Уэллса. В нем автор рассказывает об ужасном нападении марсиан на Англию с целью уничтожения всего живого и захвата территории.

В XX и XXI вв. в этом жанре было создано довольно много литературных произведений, отметим лишь наиболее известные. Роман «Метро 2033» Дмитрия Глуховского, где описывается жизнь людей, проживающих в разрушенном мегаполисе после ядерной войны. Серия книг под названием «Хроники хищных городов» Филипа Рива, в которых показана жизнь в пустыне и способы выживания через тысячу лет после глобальной катастрофы. Роман «Почтальон» Дэвида Брина, погружающий читателей в трагические и противоречивые взаимоотношения людей, чудом выживших после разрушительной войны. Серия книг «Эпоха мертвых» Андрея Круза, рассказывающая о восстании мертвецов, целью которых является уничтожить всех, кто остался в живых. Роман «Я - легенда» Ричарда Мэтисона, повествующий о периоде жизни на Земле, где главной опасностью для немногих выживших является страшная болезнь - вампиризм, и т. д. 
Все художественные произведения, написанные в этом жанре, несколько похожи по содержанию, и все они имеют один и тот же посыл - призывают читателей задуматься о своей сегодняшней жизни, о своих действиях по отношению к природе и к себе подобным, о тех ценностях, которыми живем для того, чтобы не допустить таких вымышленных фантастических катастроф в реальной жизни.

Апокалиптическая тема звучит также и в работах современных композиторов. Например, в музыкальных произведениях «Pro et contra» и «Аллилуйя» Софии Губайдуллиной настойчиво звучат эсхатологические мотивы, поскольку для нее это «реквием по всей истории человечества, как Апокалипсис» [14, с. 95]. Похожие настроения можно встретить и в других ее циклах «Еt expecto» («И чаю воскрешения мёртвых и будущего века. Аминь»), «In Erwartung» («В ожидании»- в ожидании Страшного суда). У советского композитора Алемдара Караманова апокалипсис вызывал оптимизм, по поводу того, что добро всегда одерживает верх над злом. Он создал цикл симфоний «Бысть», который сам называл «Музыкально-симфоническим Апокалипсисом» [15]. Для творчества современного русского композитора Ефрема Подгайца тема апокалипсиса вообще является сквозной, она звучит в произведении «Липс-концерт» и «Лондонской симфонии». А его симфония «Будет ласковый дождь» написана под впечатлением от прочитанного одноименного рассказа Рэя Брэдбери. Подгайц, так же как и Брэдбери, считает техноцентризм главной проблемой человечества и настойчиво «обращает внимание слушателей на острые проблемы экологии и окружающего мира» [16].

Современную апокалиптическую музыку в режиме онлайн можно услышать на «Радио Постапокалипсиса» [17]. Показательно, что эта станция ничего кроме соответствующей названию музыки вообще не вещает, поэтому прослушав ее несколько минут, вполне можно впасть в уныние и тоску, а позитивные мысли сразу сменятся на печальные, воображение будет активно рисовать самые мрачные картины. Но раз в пространстве современной массовой культуры существует такое радио, значит оно действительно кому-нибудь нужно.

В картинах многих современных художников тема конца света также прослеживается. Американский мастер Мартин Виттфут изображает животных крупным планом в ужасающей окружающей действительности [18]. Польский художник Здислав Бексиньский также известен своими картинами с мрачными постапокалиптическими сюжетами, в которых присутствуют искаженные тела, скелеты, пустыни, смерть [19]. Джон Уолтерс и Питер Бостдате, вдохновившись компьютерной игрой «Последние из нас», создают картины страшного будущего известных архитектурных достопримечательностей с помощью цифровых технологий [20]. Японский художник Tokyo Genso также с помощью компьютерных программ создает иллюстрации, где постапокалиптический мир изображается с максимальной реалистичностью, демонстрируя шокированному зрителю отдельные уголки Японии, в которых уже нет места человеку [21]. По-своему видит апокалипсис художник Рики Аллман, картины которого умышленно переполнены сложными геометрическими пейзажами, для изображения которых он использует яркие краски с темными оттенками для усиления эффекта драматизма [22].

Еще один жанр, в котором традиционно отражается тема постапокалипсиса, - это комиксы (книги в картинках). Показательно, что многие из них явились прототипами для создания очень известных фильмов, мультфильмов, компьютерных игр. Так, например, на основе комикса «Люди Икс» (авторы - Стэн Ли и Джек Кирби), было снято множество фильмов с различными вариациями в названии: «Поколение Икс», «Люди Икс: Последняя битва», «Люди Икс: Дни минувшего будущего», «Люди Икс: Апокалипсис» и еще ряд других. В 1992 г. компанией «Fох» был выпущен мультсериал «Люди Икс», где 
супергерои-мутанты не только непрерывно сражаются со всеми, кто представляет для них опасность, но и противостоят жестокому плану по захвату всего мира, разработанному мутантом Магнето. Примечательно, что в подобных комиксах, фильмах, мультфильмах, доступных массовому потребителю с самого детства, кроме глобальных проблем наглядно презентуются и повседневные социальные неурядицы. Так, критики и зрители сравнивают супергероев-мутантов с различными меньшинствами (инвалидами, людьми с иным цветом кожи, евреями, гомосексуалистами и т. д.), к которым большинство относится с боязнью, презрением, а порой и с откровенной ненавистью.

Знаменитый французский комикс «Сквозь снег» Жака Лоба и Жан-Марка Рошетта имеет очень интригующий и захватывающий сюжет. После глобальной экологической катастрофы наступает ледниковый период. Выжившие люди вынуждены жить в поезде, состоящем из 1001 вагона, который постоянно движется по планете. В поезде, который представляет проекцию социальной пирамиды, происходит восстание из бедняков из последних вагонов, которые противостоят элите, находящейся в начале поезда. Взяв за основу этот комикс, корейский режиссер Пон Чжун Хо снял постапокалиптический боевик-триллер с одноименным названием «Сквозь снег» (2013), который триумфально прошествовал по экранам десятков стран мира.

Английский комикс «Y. Последний мужчина» Брайана Вона и Пии Гуерры повествует о мире, пережившем гендерный апокалипсис. После неизвестной болезни погибают все особи мужского пола, кроме одного - Йорика. В мире наступает полный матриархат, а Йорик с несколькими спутницами отправляется в опаснейшее путешествие на поиск своей подруги, а также для выяснения причин вымирания всех остальных мужчин. В руках главного героя, которого одни хотят убить, а другие завладеть им, оказывается судьба всего человечества.

Еще один комикс, подходящий к нашей теме, написан в жанре зомбиапокалипсиса и называется «Непокорная кровь». Его авторы - Алекс Линк и Райли Россмо - выдумали ужасный мир, который захвачен смертельно опасным вирусом, превращающим людей в ходячих мертвецов, а всех живых существ - в зомбиживотных. Главный герой, уединившийся на вышке и потому чудом не заразившийся, отправляется на спасение своей семьи, которая находится вдали от него. Этот комикс можно отнести и к жанру ужасов, т. к. в нем содержатся изображения с омерзительными мертвецами, пугающими кровожадными животными, с растерзанными животными и людьми.

Вообще, комиксов по анализируемой нами теме существует великое множество. Их отличает крайняя нереальность происходящего и откровенные сцены насилия и ужаса. В рисованных историях авторы воплощают самые невероятные сюжеты, которые также заставляют задуматься о будущем. Однако комиксы, как настоящий жанр массовой культуры, более всего выполняют, как это ни парадоксально и чудовищно звучит, именно развлекательную функцию. Поскольку именно в них читателю предоставляется возможность рассматривать в деталях сцены убийства или насилия, которые к тому же можно смаковать бесконечно.

Однако единственным на сегодняшний день крайне прибыльным жанром массовой культуры, где потребитель может не только воображать или видеть картины разрушенного мира после глобальной катастрофы, но и сам принимать участие в миссиях по спасению человечества, являются компьютерные игры. В них происходит полное отожествление игрока с персонажем, который, выполняя все миссии, одерживает победу над злом, вирусами, мутантами, спасает и себя, и всю выжившую цивилизацию, при этом чувствуя себя настоящим Героем. 
Постапокалиптическая игра «Fallout» («Выпадение радиоактивных осадков») впервые была выпущена в 1997 г. С тех пор создатели значительно усовершенствовали еe, добавили красочных спецэффектов, озвучили, другими словами, сделали максимально реалистичной и современной. Действие игры происходит в мире после глобальной войны, после которой образовалась радиоактивная пустыня, а все выжившие укрылись в бункере. Одному из жителей бункера предстоит за 150 дней найти некий водный чип и принести его в убежище для жаждущих спасения людей. На протяжении всей игры участнику предстоит выполнить множество заданий и сразиться с ужасными и жестокими представителями «нового мира».

B компьютерной игре «Horizon Zero Dawn» действия происходят в мире, пережившем фатальную катастрофу тысячу лет назад. Разрушенные города теперь населяют сумевшие выжить после катастрофы звери-роботы, когда-то созданные людьми, к тому же обладающие способностью к самовоспроизводству и самосовершенствованию. Роботам противостоят первобытные человеческие племена, вооруженные лишь копьями и луками. Игра ведется от лица главной героини, которой предстоит самоотверженно бороться с механическими животными. Показательно, что эта игра была выпущена в 2017 г. и имела огромный успех, получив одобрительные отзывы со стороны критиков, которые «особо отмечали предоставленную игроку свободу, сюжет, боевую систему и проработку главной героини Элой» [23]. В 2019 г. в мире было реализовано более десяти миллионов копий игры, вследствие чего она приобрела статус самой продаваемой игры для PlayStation 4.

Показательно, что в современном отчужденном мире именно компьютерные игры набирают все большую популярность, во многом из-за общей бессознательной установки на симулятивное отношение к реальности, прошлому, настоящему и будущему, а новейшие технологии, частично компенсируя это, позволяют создать виртуальную реальность с мнимым и ложным «эффектом присутствия». Несомненно, игроков притягивают и технико-технологические новшества разработчиков, в результате они с наслаждением играют в «реальность», симулятивно участвуя в ужасной вакханалии всеобщего вымирания.

В то же время самым нераспространённый жанр, специфически отображающий постапокалиптическую тему, - это фэнтези - один из видов фантастики, основанный на сказочных сюжетах с вымышленными мифологическими героями: троллями, гномами, эльфами, драконами. Казалось бы, как можно соединить идею конца света с магией и сказочными героями? Но человеческая фантазия безгранична, а потому постапокалиптические фэнтези тоже существуют. Так, начиная с 1977 г. выпускалась серия книг «Шаннара» писателя Терри Брукса. По сюжету действие происходит в далеком будущем после ядерной войны. Выжившие - это обычные люди и все те, кто мутировал изза радиации (эльфы, дворфы, тролли). Каждая раса живет на своей территории, а весь их мир называется «Четыре земли». Технологические достижения цивилизации были уничтожены, их заменила магия, с помощью которой каждая из рас хотела стать господствующей, как это было с ядерным оружием до гибели цивилизации. Таким образом, автор проводит аналогию с настоящим и призывает читателей одуматься, пока не поздно. В США эта серия фантастических рассказов имела огромный успех, а по мотивам «Трилогии Шаннары» режиссерами Альфредом Гофом и Майлсом Милларом был снят сериал «Хроники Шаннары», а также создана компьютерная игра «Shannara».

В этой связи стоит обратить внимание и на японскую традицию создания постапокалиптических манг (японские комиксы). Знаменитая «Атака на титанов» Хадзимэ Исаямы имеет крайне необычный мифосимволический сюжет, поскольку мир в ней 
был разрушен Титанами - огромными существами, поедающими людей. Выжившие проживали на территории, окруженной тремя высокими стенами, ведь именно так они надеялись защититься от Титанов. Но великаны-каннибалы все-таки разрушили одну из стен и проникли в город, в то время как отважные солдаты и королевская стража мужественно защищали свой народ и короля.

На основе этой манги был также снят аниме-сериал, художественный фильм, а также разработаны четыре компьютерные игры. Сначала манга имела огромный успех, ведь только в 2013 г. было реализовано 20 миллионов ее копий. Однако в 2015 г. в Китае распространение «Атаки Титанов» было запрещено, на том основании, что эта манга «включает в себя сцены насилия, порнографии, терроризма и преступлений против общественной морали, которые потенциально могут подстрекать несовершеннолетних на совершение таких действий» [24]. В России, например, этот комикс и сейчас находится в свободном доступе, его можно купить во многих интернет-магазинах.

\section{Кинообразы постапокалипсиса}

Однако наиболее широко и всесторонне тема конца света в XX и начале XXI вв. оказалась представленной в самом массовом из всех искусств - кинематографе. На сегодняшний день на мировые экраны вышло более 170 фильмов и сериалов с постапокалиптическими сюжетами. Подробный обзор и анализ этих кинокартин, безусловно, заслуживают отдельного большого исследования, а здесь остановимся лишь на наиболее важных моментах. С бурным развитием теле- и киноиндустрии тема конца света довольно быстро и широко распространилась в кинематографе. А с появлением, а затем и явным доминированием визуального контента в пространстве массовой культуры люди все больше стали «мыслить» транслируемыми кино и телевидением образами, символами.

Для современного массового человека гораздо проще и привлекательней оказывается поход в кинотеатр на просмотр захватывающего двухчасового фильма с невероятными визуальными спецэффектами с целью «насладиться» представленной режиссерами, картиной гибели и способами выживания человечества, чем прочитать книгу или послушать музыку на эту же тему. Ведь при просмотре подобного рода фильмов думать практически не нужно, достаточно простого созерцания и экстремального психоэмоционального переживания в такт придумкам режиссеров и постановщиков спецэффектов. Несмотря на эти обстоятельства, все подобные киноленты все-таки несут в себе значительный нравственный смысл и воспитательный посыл. Их создатели, пусть и в экстремальной форме, но все же настойчиво призывают людей к более бережному и трепетному отношению к себе и окружающей природе, к размышлениям о возможных трагических последствиях разрушительной хозяйственной деятельности человечества. Однако абсолютное большинство современных зрителей идут в кинотеатр исключительно ради развлечения, получения экстремальных, т. е. необыденных впечатлений, к чему и сводится главное удовольствие от увиденного.

Как указывала М.С. Галина в своей статье «Старая, новая, сверхновая... Журналы фантастики на постсоветском пространстве»: «Фантастика, один из самых чутких жанров, оперативно улавливающий настроения общества...» [25]. Раз есть спрос, есть и предложение. А предложений действительно очень много. Так, на одном из общедоступных сайтов собрана подборка из ста фильмов на тему постапокалипсиса [26]. Почти все они могут быть условно разделены на виды апокалиптических и постапокалиптических сюжетов. 
Так, таинственные опасности космического происхождения (падение метеоритов, столкновение Земли с астероидами или неизвестной планетой, отравление землян ядовитыми парами кометы, страхи по поводу угасания Солнца) отражены в фильмах «Конец мира» (2021), «Смерть пришла из космоса» (1958), «Пекло» (2007), «Меланхолия» (2011), «Рыбная история» (2009). Страхи человечества перед вторжением коварных инопланетян представлены в лентах «Чужие среди нас» (1988), «Прибытие» (1996), «Война миров» (2005), «День независимости» (1996), «Чужая нация» (1996), «Люди в черном» (1997) и др. Разнообразные природные катаклизмы или «так называемый “экологический армагеддон”, который приведет к гибели человеческой цивилизации» [27, p. 263], причиной которого могут быть землетрясения, извержения вулканов, ураганы, смерчи или глобальное потепление, отражены в кинокартинах «Потоп» (2021), «Супервулкан» (2005), «Звери дикого Юга» (2012), «Послезавтра» (2004), «Сквозь снег» (2013), «День катастрофы» (2004), «Наводнение» (2007) и т. д. Катастрофические последствия глобальной ядерной войны представлены в фильмах «Нити» (1984), «Как я теперь люблю» (2013), «Почтальон» (1997), «На следующий день» (1993), «На последнем берегу» (2000). Ужасы, связанные с возможной пандемией, неизвестными вирусами, порождающими страшные заболевания и эпидемии, визуализированы в лентах «Пандемия» (2016), «Безумцы» (2010), «12 обезьян» (1995), «Штамм Андромеда» (2008), «28 недель спустя» (2007), «Заражение» (2011), «Я - легенда» (2007). Реальность нашествия зомби показана в картинах «Ночь живых мертвецов» (1990), «Батарейка» (2012), «Поезд в Пусан» (2016), «Земля мертвых» (2005), «Планета страха» (2007), «Обитель зла» (2001-2021). Опасности, которые несет в себе применение искусственного интеллекта, вырывающегося из-под контроля, а также страхи, связанные с восстанием роботов, бунтом машин представлены фильмами «Терминатор» (1984-2019), «Мир дикого Запада» (2016), «Девять» (2009), «Машина» (2013), «Хроники хищных городов» (2018) и т. д. Кошмары, связанные с нашествием нечеловеческих живых существ, представлены фильмами «Планета обезьян» (1968-2017), «Крысы: ночь ужаса» (1984), «Власть огня» (2002) и т. д. Страдания людей, связанные с острым дефицитом ресурсов, показаны в лентах «Безумный Макс» (1979-2015), «Дитя человеческое» (2006), «Водный мир» (1995) и т. д. Губительные для планеты результаты хозяйственной деятельности человека показаны в картинах «Земное ядро» (2003), «И грянул гром» (2016) и многих других.

Для более полного представления о специфике современной голливудской визуализации постапокалиптических сюжетов в пространстве массовой культуры посмотрим на некоторые фильмы более подробно. В известном научно-фантастическом фильме Стивена Спилберга «Война миров» (2005) в лучших «катастрофических» традициях Голливуда последних десятилетий массовому зрителю демонстрируется ужасное нападение марсиан на планету Земля. Следует отдать должное авторам фильма, специально акцентировавшим внимание на том, что перед нападением коварные инопланетяне тщательно изучали людей, пока те занимались своими привычными делами. Но однажды чужаки решили выйти из потаенного укрытия и захватить мир. Далее зритель с ужасом наблюдает «крушение» энергетических основ потребительской цивилизации, как будто бы специально заранее предельно сузившей для себя возможность маневра в случае непредвиденных ситуаций, когда в результате аномальной грозы отключается электричество и страна погружается в кромешную тьму. В это время главный герой фильма Рэй привозит к себе домой своих детей от бывшей супруги - сына Робби и дочь Рэйчел. От мощных ударов молний в асфальте образуются трещины, из которых появляются гигантских размеров существа на трех ногах, напоминающие роботов, которые 
истребляют людей смертельными лучами. О том, что конец света уже близок, как и в далекие ветхозаветные времена, напоминают текущие повсюду реки крови. Истошные крики убегающих людей провозглашают настоящую «агонию перед кончиной мира» $[10$, c. 73$]$. Судя по разворачивающимся событиям, у жителей города, да и в мире в целом, нет никаких шансов выжить. Везде, где бы ни прятались несчастные люди, их находят щупальца с видеодатчиками и передают сигнал инопланетному роботу, потом этих людей настигает и уничтожает треногий монстр. И только в самом конце фильма наступает неожиданная развязка. Когда большинство жителей уже уничтожено, а выживших можно пересчитать по пальцам, пришельцы вдруг замирают один за другим. Как выясняется, они умирают от вируса, находящегося на Земле, в то время как у людей уже выработан к нему иммунитет. Кровопролитная война закончена, и в этот раз человечеству удалось выжить. Несомненно, что для потребителя массовой культуры «Война миров» - зрелищный экшен со спецэффектами масштабного разрушения, сотнями смертей и угрозой крушения всей человеческой цивилизации. Для вдумчивого же и умеющего «читать между строк» зрителя «Война миров» - это еще один повод задуматься о трагической уязвимости человечества перед невидимым врагом - тоталитаризмом власти, извечной целью которого является захват лидирующего положения в мире посредством возможности применения оружия массового поражения.

Еще один кошмарный постапокалиптический мир показан в голливудском фильме режиссера Сюзанны Бир «Птичий короб» (2018). На этот раз причиной вымирания людей становятся не инопланетяне, а таинственные сущности, при одном лишь взгляде на которых люди за считанные минуты превращаются в сумасшедших самоубийц. Действие фильма происходит в США. Главная героиня - беременная художница Мэлори вместе с сестрой едет в клинику для обследования. В это время в клинике и на улице происходят массовые самоубийства, которые никто не в силах остановить: люди выбрасываются из окон, врезаются в машины на полном ходу или же убивают себя любыми другими способами. Так и произошло с сестрой Мэлори: она, увидев неведомую сущность, потеряла контроль над автомобилем, а потом намерено встала перед движущимся на нее грузовиком. Хотя в городе уже наступила полная паника, Мэлори удалось в одном из домов найти спасение себе и будущему малышу. За окном хаос, повсюду трупы, море крови, разбитые машины. В ходе жесточайшей борьбы за выживание в доме остаются в живых Мэлори, двое новорожденных детей - ее сын и дочь одной женщины, которая поддалась внушению агрессивной сущности и выпрыгнула в окно, а также мужчина, который проявляет свои чувства к художнице. На протяжении пяти лет Мэлори с возлюбленным и с двумя детьми живут в лесу, пропитание и вещи они находят в соседних домах, но запасов становится все меньше. В один из дней они получают радиосообщение о существовании неподалеку целой общины выживших, куда можно добраться по реке. Перед Мэлори дилемма: поверить Рику и отправиться в опасное путешествие или остаться здесь и надеяться на чудо. Немногочисленные сумасшедшие мародеры вынуждают Мэлори покинуть дом и отправиться в безопасное место. Возлюбленный художницы, защищая ее и детей, погибает, после чего в течение двух суток Мэлори с детьми добирается по реке до общины. Это было тяжелое испытание, т. к. главная трудность заключалась в невозможности открыть глаза. На протяжении всего пути знакомые голоса ранее умерших людей настойчиво предлагали путешественникам снять повязки и посмотреть на них. Путникам буквально на ощупь приходилось преодолевать все препятствия. Их главными помощниками были птицы - три попугая в клетке. Птицы чувствовали приближение сущностей и начинали шуметь. Так, ориентируясь на шум птиц и собственную интуицию, главная героиня с детьми 
смогла добраться до общины. Как оказалось, это была школа слепых, окруженная лесным куполом, где жили птицы, уникальные способности которых предупреждали людей об опасности. Надо отметить, что главная героиня на протяжении всего фильма называет детей просто «мальчик» и «девочка» и не проявляет к ним никаких материнских чувств. Происходит так потому, что больше, чем ужасных сущностей, Мэлори боится по-настоящему привязаться к ним, поскольку знает, что просто не сможет пережить разлуку с ними. Так Мэлори сдерживает себя почти до конца фильма и, лишь прибыв в общину выживших, дает волю своим чувствам и принимает решение дать имена детям - девочке в честь ее матери, а мальчику - в честь приемного отца.

В голливудском приключенческом боевике «Обливион» (2013) режиссера Джосефа Косински причиной массового уничтожения людей снова являются инопланетяне. Показательно, что в этом фильме массовому зрителю демонстрируется не заезженный и банальный сюжет нападения пришельцев и борьбы землян с ними, а сложное киноповествование, позволяющее на протяжении всего фильма лишь догадываться о главной авторской задумке. Условно фильм можно разделить на две части: в первой нам представлена антиутопическая жизнь людей, а во второй - настоящая.

В начале кинокартины мы видим кошмарное будущее человечества в 2077 г., когда привычный людям мир был изуродован до неузнаваемости. Разрушение инопланетянами Луны спровоцировало на Земле множество землетрясений и цунами. Люди решили отразить атаку, применив ядерное оружие, чем обрекли человечество на вымирание, а Земля стала совершенно не пригодной для жизни. Теперь крайне незначительная группа выживших людей находится на «Титане» - спутнике Сатурна. А под облаками разрушенной Земли в воздухе парят башни-станции, которые непрерывно выкачивают морскую воду, перерабатывая ее в термоядерную энергию для жителей Титана. На башне постоянно происходят нападения со стороны пришельцев - падальщиков, находящихся на Земле и до сих пор не признавших свое поражение. Атаки падальщиков отражают дроны, которыми и управляет руководитель космической станции Салли, на самом деле представляющая инопланетян-захватчиков. Иногда дроны подвергаются серьезной поломке, и тогда техник по их обслуживанию Джек вылетает на место и устраняет неполадки. За ним наблюдает и предупреждает об опасности его напарница Виктория. Вместе они очень «эффективная команда» и убеждены, что, когда их миссия закончится, их сменят другие люди, а они отправятся на Титан проживать счастливую жизнь. Причем подлинная жизнь на Титане в фильме так и не показана, только постоянно ведутся разговоры об этом «райском» месте. На этом первая часть заканчивается и начинается самая интересная - вторая.

Однажды, в очередной вылетев раз на задание, Джек замечает падение неизвестного космического корабля. Он немедленно отправляется туда и спасает одну женщину, образ которой он до этого постоянно видел в своих снах. Весь остальной экипаж дроны расстреливают. Память у Джека стерта, и он никак не может понять, что же за воспоминания он видит в снах. Все становится на свои места, когда пилот разбившегося корабля Юлия рассказывает ему всю правду. Когда-то, в 2017 г., Джек был капитаном космического корабля «Одиссей», а Виктория - его правой рукой - вторым пилотом. На борту находились еще члены экипажа в специальных капсулах для гиперсна, в том числе и Юлия. Главная ужасная интрига фильма состоит в том, что инопланетяне создали тысячи клонов Джека и Виктории, стерли им память и отправили работать на наблюдательные станции по всей обезображенной войной Земле. Оказалось, что башни-станции выкачивают воду не для людей, а для нужд пришельцев, т. к. на Титане нет никаких выживших. Все уцелевшие реальные люди находятся на Земле, а инопланет- 
ные захватчики презрительно именуют их «падальщиками». Поэтому они и атакуют башни, забирающие последнюю живительную влагу. Однажды, захватив Джэка и Юлию в плен, падальщики делятся с ними планом по спасению человечества. Джек и лидер уцелевших людей осуществляют этот хитрый, героический и смертельный для них обоих план. Главный космический центр управления пришельцев уничтожен, человечество спасено.

Еще один постапокалиптический мир в жанре фэнтези визуализирован голливудскими мастерами в фантастическом боевике «Власть огня» (2002) режиссера Роба Боумана. По сюжету картины в Лондоне бригада строителей прокладывает ветку метрополитена. По указанию руководства строители бурят в заданном направлении и обнаруживают таинственную пещеру. В это время к матери, которая и руководит этой бригадой, приходит ее сын с печальными вестями. Мальчик обнаруживает в пещере огнедышащего дракона, на беду случайно разбуженного обреченными теперь на ужасную смерть строителями. Из всей бригады в живых остался только ребенок. Выбравшись в наш мир, драконы стремительно начинают размножаться и истреблять всех живых существ. Год за годом люди пытаются сопротивляться тварям, но не могут найти действенное оружие против них. Тогда в ход было пущены ядерные заряды. Это не смогло убить драконов, но зато послужило причиной вымирания большей части человечества. Массовый зритель с ужасом видит постапокалиптический разрушенный и обезлюдевший Лондон, над которым рыскают драконы, выискивая выживших. Спустя 20 лет после пробуждения дракона выжившие люди во главе с тем самым мальчиком Куинном, который первым увидел чудовище, смогли обосноваться в замке и создать общину. Они так живут уже много лет и надеются, что смогут пережить драконов. Лишь спустя годы, с помощью усовершенствованных стрел, имеющих мощное взрывное воздействие, трое самых отважных героев одерживают победу над драконом. У людей появляется надежда вернуться к прежней жизни.

Таким образом, мы лишь частично проанализировали спектр сюжетов современной массовой культуры, посвященных древнейшей теме конца света. Можно сделать вывод о неуклонной виртуализации этой проблематики, которая все активнее завоевывает медиапространство человеческой цивилизации. С развитием теле- и киноиндустрии кинематограф прочно входит в нашу жизнь. Тема апокалипсиса и постапокалипсиса необычайно широко распространилась в современном кинематографе и отличается завидным многообразием сюжетов, визуализирующих зловещие и пророческие картины грядущих катастроф и неминуемого полного или же частичного вымирания человечества. «Творчески» развивая апокалиптические сюжеты древнейших мифологий и религий, современные экранизации на тему грядущего и, увы, уже неизбежного конца света неизменно выполняют сразу несколько идеологически важных функций (коммуникативную, познавательную, транслирующую, сублимационную, а главное - развлекательную), без которых общество потребления просто немыслимо. Более того, в современном мире постапокалипсис все чаще рассматривается не как «вырождающаяся утопия на самом деле вовсе не утопия, а скорее идеология» $[28$, с. 261], которая становится способом визуализации наиболее острых социальных противоречий и трендов, под масками которых скрываются «подлинные субъекты исторического процесса в мире карнавальной «постистории» [29, с. 18] и «кровавой хоррологии цивилизации» [30, c. 46]. Рассмотрев, как преломляется тема апокалипсиса и постапокалипсиса в различных жанрах массовой культуры, можно констатировать, что современное массовое общество слишком уж с явным удовольствием «потребляет» сюжеты хаоса, разрушения и смерти. Об этом, в том числе, говорят многочисленные киноленты с постапока- 
липтическими сюжетами, наполненные впечатляющим визуальным рядом, поражающим воображение спецэффектами, сценами разрушения городов и целых континентов, а также массовой гибели природы и людей. Такого рода культурная продукция представляет закономерное воплощение танатологических тенденций современной массовой культуры, неизменно усиливающихся от десятилетия к десятилетию.

\section{СПИСОК ЛИТЕРАТУРЫ}

1. Хренов Н.А. К истории становления науки о культуре: Освальд Шпенглер (к 100-летию выхода книги «Закат Европы») // Культура культуры. - 2020. - № 1. URL: https://cyberleninka.ru/article/n/k-istoriistanovleniya-nauki-o-kulture-osvald-shpengler-k-100-letiyu-vyhoda-knigi-zakat-evropy (дата обращения 12.06.2021).

2. Коренная О.Б. Ф.А. Степун о книге О. Шпенглера «Закат Европы» // Вестник Амурского государственного университета. Серия «Гуманитарные науки». - 2013. - № 62. URL: https://cyberleninka.ru/article/n/f-a-stepun-o-knige-o-shpenglera-zakat-evropy (дата обращения 12.06.2021).

3. Шпенглер О. Закат Европы. Очерки морфологии мировой истории. URL: http://files.schoolcollection.edu.ru/dlrstore/cfcb4d14-489c-4a82-9bcf-c4fb4062fda8/\%5BCIVSal1011_10-03-11-

U2\%5D_\%5BTS_52\%5D.html (дата обращения 12.06.2021).

4. Тойнби А. Постижение Истории. - М.: Прогресс, 1991. - 736 с.

5. Сорокин П.А. Человек. Цивилизация. Общество. - М.: Политиздат, 1992. -542 с.

6. Ковачич Е. Питирим Сорокин о будущем цивилизаций // Российская академия наук. URL: http://www.ras.ru/news/shownews.aspx?id=c80476c5-4a04-44b5-b0d0-79d687f37c48 (дата обращения 12.06.2021).

7. Огурцов А.П. Симулякр // Новая философская энциклопедия. URL: https://iphlib.ru/ library/collection/newphilenc/document/HASHe582c0684b9932e2c8eae5?p.s=TextQuery (дата обращения 12.06.2021).

8. Бодрийяр Ж. В тени молчаливого большинства, или Конец социального. - Екатеринбург: Изд-во Урал. ун-та, 2000. - 96 с.

9. Сиоран Э. Искушение существованием. - М.: Республика: Палимпсест, 2003. - 431 с.

10. Бодрийяр Ж., Сиоран Э. Матрица Апокалипсиса. Последний закат Европы. - М.: Алгоритм, 2015. $272 \mathrm{c}$.

11. Бьюкенен П.Дж. Смерть Запада - М.: АСТ, 2003. - 444 c.

12. Pitteti C. Uses of the end of the world: apocalypse and postapocalypse as narrative modes // Science Fiction Studies. - 2017. - V. 44. - № 3. - P. 437-454.

13. Yaren Ö. Post-human aesthetics of apocalypse // AM Journal of Art and Media Studies. - 2019. - № 19. P. 77-83.

14. Холопова В., Рестаньо Э. София Губайдулина. - М.: Композитор, 1996. - 329 с.

15. Синельникова О.В., Тюлюнева А.И. Апокалиптические мотивы в творчестве отечественных композиторов эпохи постмодерна // МНИЖ. - $2014 . \quad$ - № 1-4 (20). URL: https://cyberleninka.ru/article/n/apokalipticheskie-motivy-v-tvorchestve-otechestvennyh-kompozitorovepohi-postmoderna (дата обращения 12.06.2021).

16. Камышанова М. В. Особенности воплощения эсхатологической темы в искусстве. Третья симфония Ефрема Подгайца // Вестник Башкирского ун-та. - 2012. - № 2. URL: https://cyberleninka.ru/article/n/osobennosti-voploscheniya-eshatologicheskoy-temy-v-iskusstve-tretyasimfoniya-efrema-podgaytsa (дата обращения 12.06.2021).

17. Радио «Апокалипсис». URL: https://101.ru/radio/user/666909 (дата обращения 12.06.2021).

18. Wittfooth M. Selected works. 2009-2021. URL: https://www.martinwittfooth.com (дата обращения 12.06.2021).

19. Бексиньский 3. WikiArt. Энциклопедия визуальных искусств. URL: https://www.wikiart.org/ru/zdzislav-beksinskiy (дата обращения 12.06.2021).

20. Знаменитые достопримечательности со всего мира до и после апокалипсиса // Камералабс. URL: https://cameralabs.org/6849-znamenitye-dostoprimechatelnosti-so-vsego-mira-do-i-posle-apokalipsisa (дата обращения 12.06.2021).

21. Мир после апокалипсиса в иллюстрациях Tokyo Genso // Камералабс. URL: https://cameralabs.org/6455-mir-posle-apokalipsisa-v-illyustratsiyakh-tokyo-genso (дата обращения 12.06.2021).

22. Ricky Allman. URL: https://www.Rickyallman.com (дата обращения 12.06.2021). 
23. Horizon zero dawn. URL: https://ru.wikipedia.org/wiki/Horizon_Zero_Dawn (дата обращения 12.06.2021).

24. Атака на титанов. URL: https://ru.wikipedia.org/wiki/\%D0\%90\%D1\%82\%D0\%B0\%D0\% BA\%D0\%B0_\%D0\%BD\%D0\%B0_\%D1\%82\%D0\%B8\%D1\%82\%D0\%B0\%D0\%BD\%D0\%BE\%D0\%B2 (дата обращения 12.06.2021).

25. Галина М.С. Старая, новая, сверхновая... Журналы фантастики на постсоветском пространстве // Новый мир. - 2006. - № 8. URL: https://magazines.gorky.media/novyi_mi/2006/8/staraya-novayasverhnovaya.html (дата обращения: 12.06.2021).

26. 100 действительно крутых фильмов про постапокалипсис // Лайфхакер. URL: https://lifehacker.ru/filmy-pro-

postapokalipsis/?utm_referrer=https\%3A\%2F\%2Fzen.yandex.com\&utm_campaign=dbr (дата обращения 12.06.2021).

27. Cardoso P., Leather S.R. Predicting a global insect apocalypse // Insect Conservation and Diversity. 2019. - № 12 (4). - P. 263-267. DOI: 10.1111/icad.12367.

28. Bussière K. Survival is insufficient: degenerate utopian nostalgia in popular culture post-apocalyptic fiction // The Australasian Journal of Popular Culture. - 2020. - № 9 (2). - P. 261-275. DOI: 10.1386/ajpc_00031_1

29. Некита А.Г., Маленко С.А. «Все мы там будем»: «Судная ночь» как пример эгалитарной идеологии кровавого, «санационного» карнавала // Векторы благополучия: экономика и социум. - 2020. № 1 (36). - C. 12-19. URL: https://jwt.su/journal/article/view/987/1025 (дата обращения 12.06.2021).

30. Malenko S.A., Nekita A.G. Horror films in unconscious anthropological strategies of biopower // Anthropological Measurements of Philosophical Research. - 2018. - № 13. - P. 41-51. DOI: 10.15802/ampr.v0i13.122984

Поступила 13.06.2021 г. 
UDC 316.723

\title{
POST-APOCALYPSE VISUALIZATION STRATEGIES IN MODERN POPULAR CULTURE
}

\author{
Andrey G. Nekita, \\ beresten@mail.ru \\ Sergey A. Malenko, \\ olenia@mail.ru \\ Elena P. Suslova, \\ polos123@mail.ru \\ Yaroslav-the-Wise Novgorod State University, \\ 41, B. St. Petersburgskaya street, Veliky Novgorod, 173003, Russia
}

Andrey G. Nekita, Dr. Sc., professor, Yaroslav-the-Wise Novgorod State University.

Sergey A. Malenko, Dr. Sc., professor, head of the Department of philosophy, cultural studies and sociology, Yaroslav-the-Wise Novgorod State University.

Elena P. Suslova, student, Yaroslav-the-Wise Novgorod State University.

Relevance. Total expansion of screen culture creates new trends that cause the emergence of a new anthropological situation. Modern man ceases to enjoy the familiar images that connect his fantasies with reality. He deliberately and demonstratively seeks to surround himself with destructive images, each time emphasizing the increasing severity of the problems of modern civilization. Therefore, the emergence and rapid development of the post-apocalypse genre serves as a visualization of the fantasies of the average person about the urgent need to end the suffering of man and nature within the established forms of civilizational communication. The aim: to analyze the peculiarity of post-apocalyptic plots in contemporary art and cinema, based on the theoretical heritage of modern times. Methods. The research is based on comparative, psychoanalytic and semiotic methods of interpretation of a wide field of modern mass culture. Results. The idea of the end of history became particularly relevant at the beginning of the twentieth century, when a comprehensive socio-cultural crisis broke out in Europe. Outstanding minds have tried to answer the most complex contradictions that humanity has faced for the first time. The growing social contradictions are increasingly seen as signs of the coming end of a civilization that is mired in unification, the irresponsibility of power and the passivity of the masses. Such reflection prepared the formation of the artistic experience of visualizing the fundamental contradictions of civilization, which were especially aggravated at the turn of the XX-XXI centuries. Despite the predominantly recreational nature of modern mass art, it chooses this theme as the main direction of its development. Literature, music, painting, comics, animation, and computer games actively use the plots of the end of history to recreate the tense expectation of the imminent reckoning of humanity for its irresponsible attitude to nature and man. The modern film industry occupies a special place in solving this problem, because it has at its disposal exceptional means of expression and the most mass audience. Findings. The fantastic popularity of the post-apocalypse theme goes beyond the usual cultural industries and confidently turns into a form of ideological visualization of the key socio-cultural contradictions of the era. Such management technology is regarded by the authors as a propaedeutics of a new quality of modern civilization, forcibly severing genetic ties with nature, culture and tradition.

Key word: Post-apocalypse, ideology, art, mass culture, cinema, crisis of civilization, end of history.

\section{REFERENCES}

1. Khrenov N.A. K istorii stanovleniya nauki o kulture: Osvald Shpengler (k 100-letiyu vykhoda knigi «Zakat Evropy») [On the history of the formation of the science of culture: Oswald Spengler (on the $100^{\text {th }}$ anniversary of the publication of the book «The Decline of Europe»)]. Kultura kultury, 2020, no. 1. Available at: 
https://cyberleninka.ru/article/n/k-istorii-stanovleniya-nauki-o-kulture-osvald-shpengler-k-100-letiyuvyhoda-knigi-zakat-evropy (accessed 12 June 2021).

2. Korennaya O.B. F.A. Stepun o knige O. Shpenglera «Zakat Evropy» [F.A. Stepun about O. Spengler's book «The Decline of Europe»]. Vestnik Amurskogo gosudarstvennogo universiteta. Seriya «Gumanitarnye nauki», 2013, no. 62. Available at: https://cyberleninka.ru/article/n/f-a-stepun-o-knige-o-shpenglera-zakatevropy (accessed 12 June 2021).

3. Shpengler O. Zakat Evropy. Ocherki morfologii mirovoy istorii [The decline of Europe. Essays on the morphology of world history]. Available at: http://files.school-collection.edu.ru/dlrstore/cfcb4d14-489c-4a829bcf-c4fb4062fda8/\%5BCIVSal1011_10-03-11-U2\%5D_\%5BTS_52\%5D.html (accessed 12 June 2021).

4. Toynbi A. Postizhenie istorii [Understanding history]. Moscow, Progress Publ., 1991. 736 p.

5. Sorokin P.A. Chelovek. Tsivilizatsiya. Obshchestvo [Person. Civilization. Society]. Moscow, Politizdat Publ., 1992. 542 p.

6. Kovachich E. Pitirim Sorokin o budushchem tsivilizatsiy [Pitirim Sorokin on the future of civilizations]. Rossiyskaya akademiya nauk. Available at: http://www.ras.ru/news/shownews.aspx?id=c80476c5-4a0444b5-b0d0-79d687f37c48 (accessed 12 June 2021).

7. Ogurtsov A.P. Simulyakr [Simulacrum]. Novaya filosofskaya entsiklopediya. Available at: https://iphlib.ru/library/collection/newphilenc/document/HASHe582c0684b9932e2c8eae5?p.s=TextQuery (accessed 12 June 2021).

8. Bodriyar Zh. V teni molchalivogo bolshinstva, ili Konets sotsialnogo [In the shadow of the silent majority, or The End of the Social]. Yekaterinburg, Ural University Publ., 2000. 96 p.

9. Sioran E. Iskushenie sushchestvovaniem [The temptation of existence]. Moscow, Respublika Publ., Palimpsest Publ., 2003. 431 p.

10. Bodriyar Zh., Sioran E. Matritsa Apokalipsisa. Posledniy zakat Evropy [Matrix of the Apocalypse. The last sunset of Europe]. Moscow, Algoritm Publ., 2015. 272 p.

11. Byukenen P.Dzh. Smert Zapada [Death of the West]. Moscow, AST Publ., 2003. 444 p.

12. Pitteti C. Uses of the End of the World: Apocalypse and postapocalypse as narrative modes. Science Fiction Studies, 2017, vol. 44, no. 3, pp. 437-454.

13. Yaren Ö. Post-human aesthetics of apocalypse. AM Journal of Art and Media Studies, 2019, no. 19, pp. 77-83.

14. Kholopova V., Restano E. Sofiya Gubaydulina [Sofia Gubaidulina]. Moscow, Kompozitor Publ., 1996. 329 p.

15. Sinelnikova O.V., Tyulyuneva A.I. Apokalipticheskie motivy v tvorchestve otechestvennykh kompozitorov epokhi postmoderna [Apocalyptic motifs in the works of Russian composers of the postmodern era]. MNIZH, 2014, no. 1-4 (20). Available at: https://cyberleninka.ru/article/n/apokalipticheskie-motivy-vtvorchestve-otechestvennyh-kompozitorov-epohi-postmoderna (accessed 12 June 2021).

16. Kamyshanova M.V. Osobennosti voploshcheniya eskhatologicheskoy temy v iskusstve. Tretya simfoniya Efrema Podgaytsa [Features of the implementation of the eschatological theme in art. The Third Symphony by Efrem Podhaits]. Vestnik Bashkirskogo universiteta, 2012, no 2 . Available at: https://cyberleninka.ru/article/n/osobennosti-voploscheniya-eshatologicheskoy-temy-v-iskusstve-tretyasimfoniya-efrema-podgaytsa (accessed 12 June 2021).

17. Radio «Apokalipsis» [Radio «Apokalipsis»]. Available at: https://101.ru/radio/user/666909 (accessed 12 June 2021).

18. Wittfooth M. Selected works. 2009-2021. Available at: https://www.martinwittfooth.com (accessed 12 June 2021).

19. Beksinskiy Z. WikiArt. Entsiklopediya vizualnykh iskusstv [Encyclopedia of visual arts]. Available at: https://www.wikiart.org/ru/zdzislav-beksinskiy (accessed 12 June 2021).

20. Znamenitye dostoprimechatelnosti so vsego mira do i posle apokalipsisa [Famous landmarks from around the world before and after the apocalypse]. Kameralabs. Available at: https://cameralabs.org/6849znamenitye-dostoprimechatelnosti-so-vsego-mira-do-i-posle-apokalipsisa (accessed 12 June 2021).

21. Mir posle apokalipsisa v illyustratsiyakh Tokyo Genso [The World after the Apocalypse in illustrations by Tokyo Genso]. Kameralabs. Available at: https://cameralabs.org/6455-mir-posle-apokalipsisa-villyustratsiyakh-tokyo-genso (accessed 12 June 2021).

22. Ricky Allman. Available at: https://www.Rickyallman.com (accessed 12 June 2021).

23. Horizon Zero Dawn. Available at: https://ru.wikipedia.org/wiki/Horizon_Zero_Dawn (accessed 12 June 2021).

24. Ataka na titanov [Attack on the Titans]. Available at: https://ru.wikipedia.org/wiki/\%D0\%90\% D1\%82\%D0\%B0\%D0\%BA\%D0\%B0_\%D0\%BD\%D0\%B0_\%D1\%82\%D0\%B8\%D1\%82\%D0\%B0\%D0 $\% \mathrm{BD} \% \mathrm{D} 0 \% \mathrm{BE} \% \mathrm{D} 0 \% \mathrm{~B} 2$ (accessed 12 June 2021). 
25. Galina M.S. Staraya, novaya, sverkhnovaya... Zhurnaly fantastiki na postsovetskom prostranstve [Old, new, supernova ... Science fiction magazines in the post-Soviet space]. Novy mir, 2006, no. 8. Available at: https://magazines.gorky.media/novyi_mi/2006/8/staraya-novaya-sverhnovaya.html (accessed 12 June 2021).

26. 100 deystvitelno krutykh filmov pro postapokalipsis [100 really cool movies about the post-apocalypse]. Layfkhaker. Available at: https://lifehacker.ru/filmy-pro-postapokalipsis/?utm_referrer=https\%3A\%2F\%2 Fzen.yandex.com\&utm_campaign=dbr (accessed 12 June 2021).

27. Cardoso P., Leather S.R. Predicting a global insect apocalypse. Insect Conservation and Diversity, 2019 , no. 12 (4), pp. 263-267. DOI: 10.1111/icad.12367

28. Bussière K. Survival is insufficient: degenerate utopian nostalgia in popular culture post-apocalyptic fiction. The Australasian Journal of Popular Culture, 2020, no. 9 (2), pp. 261-275. DOI: 10.1386/ajpc_00031_1

29. Nekita A.G., Malenko S.A. «We'll all be there»: «the purge» as an example of egalitarian ideology in a bloody, «sanitary» carnival. Journal of Wellbeing Technologies, 2020, no. 1 (36), pp. 12-19. In Rus. Available at: https://jwt.su/journal/article/view/987/1025 (accessed 12 June 2021).

30. Malenko S.A., Nekita A.G. Horror films in unconscious anthropological strategies of biopower. Anthropological Measurements of Philosophical Research, 2018, no. 13, pp. 41-51. DOI: 10.15802/ampr.v0i13.122984

Received: 13 June 2021. 